\title{
Climate Sensitivity of Marine Energy
}

\author{
Dr Gareth P. Harrison* and Dr A. Robin Wallace \\ School of Engineering \& Electronics, University of Edinburgh, \\ Mayfield Rd, Edinburgh EH9 3JL, UK \\ Telephone: +441316505583 \\ Fax: $\quad$ +441316506554 \\ E-mail: Gareth.Harrison@ed.ac.uk \\ (*Corresponding author)
}

\begin{abstract}
Marine energy has a significant role to play in lowering carbon emissions within the energy sector. Paradoxically, it may be susceptible to changes in climate that will result from rising carbon emissions. Wind patterns are expected to change and this will alter wave regimes. Despite a lack of definite proof of a link to global warming, wind and wave conditions have been changing over the past few decades. Changes in the wind and wave climate will affect offshore wind and wave energy conversion: where the resource is constrained, production and economic performance may suffer; alternatively, stormier climates may create survival issues. Here, a relatively simple sensitivity study is used to quantify how changes in mean wind speed - as a proxy for wider climate change - influence wind and wave energy production and economics.
\end{abstract}

Keywords: Marine energy, wave energy, wind energy, wind climate, wave climate, climate change.

\section{Introduction}

Marine energy has a key role to play in meeting long term renewable energy targets as part of the drive to a low carbon economy. This is particularly true in the United Kingdom which possesses significant marine energy resources with the most favourable sites tending to be located off the Scottish north and west coasts. With mean wave power in excess of $50 \mathrm{~kW} /$ metre of wave front, Scotland's offshore wave power potential is estimated at $14 \mathrm{GW}$ and could provide some $45 \mathrm{TWh} /$ year. Similarly, offshore wind potential is some 25 $\mathrm{GW}(82 \mathrm{TWh} / \mathrm{year})$ and tidal stream around $7.5 \mathrm{GW}(33.5 \mathrm{TWh} / \mathrm{yr})$ [1].

While marine energy is being developed in order to limit or avoid climate change, its reliance on the natural environment means that it may be vulnerable to changes in climate that result from rising carbon emissions. Marine technologies share this risk with other renewable sources including hydropower [2] and wind [3]. With evidence of a changing marine climate over recent decades and the suggestion of a link to global warming [4], closer examination is justified. 


\section{Changing Offshore Climate}

From the late 1980s the trend of increasing wave height in the north east Atlantic has been reported [5]-[6]. Suggested increases in mean wave height of some $2 \%$ per year have been backed up by other sources that indicate changes of $30-50 \%$ over 30 years. While the early studies (e.g. [6]) were unable to identify local wind speed trends to explain the greater wave heights, there was recognition that local wave conditions are a complex blend of local and distant wind activity [7]. Investigations turned to broader climate conditions for explanations and found connections between wave heights and the north-south atmospheric pressure gradient in the north Atlantic [7]. Recent analysis of European offshore wind speeds [8] has identified changes over the past 40 years such as UK winter wind speeds rising by 15 to $20 \%$ over that period.

As much of this work was based on in-situ data from buoys and weather ships, identification of underlying changes in weather patterns from this data is difficult given poor spatial data coverage, few long-term series and observational practice changes [9]. Several approaches have been used to avoid such difficulties. The first is 'hindcasting' in which wave models are driven by historic weather data in order to develop a wave climate history, e.g. [10], [11]. In [10], the wave model was then used to project changes in wave climate by driving it with data from a steady-state $\left(\mathrm{CO}_{2}\right.$ doubling) climate change experiment, although the result was not conclusive. The second approach has been to use atmospheric proxies for wave heights for which regressions between significant wave height and sea level pressure [12] and the North Atlantic Oscillation (NAO) [9] have been employed; again, these have been used to project future wave conditions.

To date, however, there has been no investigation of the impacts of changes in wind and wave climate on marine energy.

\section{Marine Energy Impacts}

Alteration of wind patterns is a widely expected anticipated outcome of climate change albeit an uncertain one given the inconsistency between General Circulation Models (GCMs) and their physical representations [13]. On an annual basis relatively minor changes are forecast UK-wide [13], although there are regional and seasonal trends: southern and central UK winter wind speeds are forecast to rise by up to $10 \%$ while changes in windier Scotland appear minimal. Elsewhere in the world, the United States may see wind speed reduce by between 3\% [3] and 20\% [14] over the next 50 years. Offshore winds will also change and given the cubic relationship between wind speed and wind energy and the capability of wind turbines capture energy only from specific wind speed ranges, changes in wind speed have implications for the production and economics of offshore wind developments (Figure 1). It has been projected that a 10\% change in wind speeds could alter energy yields by 13 to $25 \%$, dependent on the site and season [15].

As ocean waves are predominately the result of wind action, changes in wind patterns will ultimately alter 
wave regimes. With available wave energy related to wind speed by the $5^{\text {th }}$ power [16], there are potentially significant consequences for wave energy (Figure 1). Like wind turbines, wave energy converters (WECs) are designed to capture energy from specific wave height, period and direction ranges. Resource changes will affect energy capture: where the resource is restricted there may be reductions in energy production and consequent economic impacts (particularly where this coincides with high energy price periods); where the wave resource increases it may enhance production but the associated increase in extreme waves (as suggested in [12] and elsewhere) may pose a greater threat to device survival.

It is anticipated that changes in wave climate will mainly affect wave energy converters. However, specific marine current or tidal stream devices may be affected by increased wave activity [17] or by changes in ocean circulation.

Sea level rise is a frequently quoted outcome of climate change and it is expected that sea levels around the UK will increase by up to $36 \mathrm{~cm}$ by 2080 [13]. While devices that are moored in deeper water might experience limited impacts, shoreline-based devices could be affected by raised water levels particularly as less energy will be dissipated.

\section{Evaluating Marine Energy}

\subsection{Wind Energy}

The power in the wind varies with the cube of the wind speed $(U, \mathrm{~m} / \mathrm{s})$ according to [18]:

$$
P=\frac{1}{2} \rho U^{3}
$$

where $\mathrm{P}$ is the power per unit area $\left(\mathrm{P} / \mathrm{m}^{2}\right)$ and $\rho$ is air density. Appraisal of wind power projects focuses on the available resource as indicated by anemometry records from the site (or nearby), either in its raw format or through fitting to a Weibull distribution. Turbine output is defined by production curves which specify output over the wind speed range between the cut-in and cut-out speeds. When combined with the wind speed information, production and, with appropriate data, the economic performance can be estimated.

\subsection{Wave Energy}

Waves are created by the transfer of energy from wind flowing over water bodies. The energy transfer defines the size of waves and this is dependent on the strength and duration of the wind and the available fetch. Wave power levels may exceed $1000 \mathrm{~kW}$ per metre of wave front $(\mathrm{kW} / \mathrm{m})$ although mean power levels off the Scottish coast approach $70 \mathrm{~kW} / \mathrm{m}$ [19]. The power in the waves varies with the square of the wave height and linearly with wave period; it may be defined as [19]: 
$P=0.49 H_{S}{ }^{2} T_{e}$

where $P$ is power (kW/m of wave front), $H_{\mathrm{S}}$ is the significant wave height $(\mathrm{m})$ and $T_{\mathrm{e}}$ the wave energy period (s). $H_{\mathrm{S}}$ and $T_{\mathrm{e}}$ are representative of the wide spectrum of waves of different heights, periods and directions that make up real seas. Together they allow the specification of a range of 'sea states' that have given probability of occurrence based on the joint coincidence of $H_{\mathrm{S}}$ and $T_{\mathrm{e}}$. These are often illustrated using scatter diagrams as Figure 2 illustrates for a site near the Shetland Isles $\left(61.4^{\circ} \mathrm{N}, 0.7^{\circ} \mathrm{W}\right)[20] . H_{\mathrm{S}}$ is defined as four times the root-mean-square (RMS) elevation of the sea surface $\left(H_{\mathrm{rms}}\right)$ :

$H_{S}=4 H_{\mathrm{rms}}=4 \sqrt{m_{0}}$

where $m_{0}$ is the zeroeth moment (or variance) of the wave spectrum. Energy period $T_{\mathrm{e}}$ is one of several representative wave period measures in use although it is favoured for wave energy approaches as it weights waves according to spectral energy content [19]:

$T_{e}=m_{-1} / m_{0}$

where $m_{-1}$ is the reciprocal of the first spectral moment (the mean frequency).

The standard approach to appraising WEC output and economics is described by Thorpe [21] and a slightly simplified version is shown in Figure 3. For the assumed location of the WEC, the wave resource record allows the identification of a range of sea states $\left(H_{\mathrm{S}}, T_{\mathrm{e}}\right.$ and direction) that are applicable for a given portion of the year. For each sea state, the characteristics of an individual device will allow an estimate of capture efficiency and hence output. The weighted average of the output during each sea state provides the annual production estimate with the economics following from that.

\section{Modelling Climate Impacts}

To some extent this work is at a similar stage to climate impact studies with hydropower in the late 1980s which used uniform changes in precipitation and temperature to assess river flow and hence hydropower production sensitivity. They allowed the identification of major influences and comparisons between different river systems. Unlike the early hydro studies, however, climate modelling is now much more advanced with General Circulation Models (GCMs) becoming increasingly sophisticated. The wind field outputs from GCMs have been used for changes in onshore wind potential either directly [3] or using regional climate models [14]. Such an approach could be used to characterise wind changes offshore. In a similar fashion to [10], these could then be used to drive a wind-wave model to provide wave information. An alternative would be to utilise pressure pattern data from GCMs and forecast wind and wave climate 
from regression models. A significant drawback of these approaches is that they require significant data volumes and computational capability. Assessment of future susceptibility will be complicated by the variance between projections from GCMs and the limited confidence in their wind speed estimates.

In many fields, sensitivity studies are often the first port of call for risk assessment as they are generally readily understood and straight-forward. As a first approximation, the climate response of wind and wave energy conversion can be assessed using changes in mean wind speeds. For wind power, the use of wellknown wind distributions makes this a relatively easy and simple adaptation of the normal appraisal process. For WECs, the changes are more involved but use of a common wind-wave model allows the appraisal methodology to be adapted as shown in Figure 4.

\subsection{Wind Speed Distribution}

A range of models have been used to describe the wind resource including the well-known Weibull distribution. A special case of this, the Rayleigh distribution, is commonly used and is defined solely by the mean wind speed $\bar{U}[18]$ :

$$
p(U)=\frac{\pi}{2}\left(\frac{U}{\bar{U}^{2}}\right) \exp \left[-\frac{\pi}{4}\left(\frac{U}{\bar{U}}\right)^{2}\right]
$$

Here $p(U)$ is the probability of occurrence of wind speed $U$ and when modelled incrementally, (5) gives the probability and, for a given period, the duration of time (in hours) for which each wind speed increment is experienced. Use of the appropriate wind turbine output at each increment and summation across all increments provides an estimate of energy production in the period.

\subsection{Wind-Wave Model}

The relationship between wind and wave conditions can be defined using the classic Pierson-Moskowitz (PM) spectrum [22]. This describes fully-developed (steady state) wind-created seas, that may occur when the wind has been blowing over a long period (6-18 h) and fetch (200-600 km). The spectrum is empirically derived and uses the wind speed, $U_{0}$ (at a height of $19.5 \mathrm{~m}$ above mean sea level) as the single parameter that defines the energy spectrum of wave energies [22]:

$$
S(\omega)=0.0081 g^{2} \omega^{-5} \exp \left[-0.74\left(\frac{g}{U_{0} \omega}\right)^{4}\right]
$$

where $S(\omega)$ is the spectral energy as a function of frequency, $\omega$ (rads). Practical use is through determination of $H_{\mathrm{S}}$ and $T_{\mathrm{e}}$ through analysis of the spectral moments using (3) and (4); these give [19]: 
$H_{\mathrm{S}}=0.0212 \cdot U_{0}^{2}$

$T_{\mathrm{e}}=0.625 \cdot U_{0}$

Equations (7) and (8) specify significant wave height and wave period (and using (2) wave power) for any given wind speed. Across a range of wind speeds this generates a single curve on an $\left(H_{\mathrm{S}}, T_{\mathrm{e}}\right)$ scatter diagram as Figure 2 shows. It is evident that the PM spectrum does not depict the full range of $H_{\mathrm{S}}$ and $T_{\mathrm{e}}$ combinations possible. However, they are accepted as being reasonable approximations given the relative paucity of data and feature heavily in wave power research. In itself the PM spectrum is not sufficient for inferring changes as particular wind speeds and accordingly, wave heights/periods exist for only a fraction of the year. A fuller representation of the range of conditions is achieved by combination with the Rayleigh wind speed distribution.

\subsection{Wave Energy Distribution}

To draw together the wind and wave spectra, each incremental value of wind speed defines a sea state according to the PM spectrum. Accordingly, the Rayleigh distribution creates a series of wave height/period pairs and wave powers over the wind speed range. It is assumed that the modelled wind speeds persist for a minimum period necessary for fully developed seas which is reasonable as a first approximation.

Alteration of the mean wind speed specifying the Rayleigh distribution will not alter the magnitudes of the wave power as these are fixed by the incremental wind speed value. Rather, the probability of a given sea state and power level will change; this alters the hourly duration and the energy output over the period. Summation across all wind speed increments provides the total wave energy available with device-specific efficiency data providing estimates of production and, in turn, economic performance.

In this way, the alteration of mean wind speed by defined amounts provides a proxy for the sensitivity of wind and wave energy conversion to changes in climate.

\section{Western Scotland Case Study}

The case study focuses on the wind and wave climate off the west coast of Scotland as, in the long term, some of the best opportunities for large-scale marine energy deployment will be here. The assessment method set out in the previous section was implemented in spreadsheet form. The wind speed was defined in $0.25 \mathrm{~m} / \mathrm{s}$ increments (up to $30 \mathrm{~m} / \mathrm{s}$ ) with the probability of occurrence and duration calculated from (5). These were used directly for the wind assessment, while Equations (2)-(4) and (7)-(8) provided $H_{\mathrm{S}}, T_{\mathrm{e}}$ and wave power to estimate annual wave climate. 
In order to maintain simplicity, the mean annual wind speed (at $19.5 \mathrm{~m}$ ) was estimated at $10 \mathrm{~m} / \mathrm{s}$ which is reasonably close to data given in [23] for a point in the Atlantic at $54^{\circ} \mathrm{N}, 22^{\circ} \mathrm{W}$. While this lies somewhat to the west and south of the Scottish coast, it is a representative value as the PM spectrum assumes the same wind speed across the full fetch.

\subsection{Wind Turbine}

The device chosen for analysis is the 3 MW Vestas V90 [24] that possesses a $90 \mathrm{~m}$ diameter rotor at $65 \mathrm{~m}$ hub height. The corrected mean wind speed at hub height was found to be just over $11 \mathrm{~m} / \mathrm{s}$ using the power law profile [18]:

$U_{65}=U_{19.5} \frac{\ln \left(h_{65} / z_{0}\right)}{\ln \left(h_{19.5} / z_{0}\right)}$

where $h_{65}$ and $h_{19.5}$ are the hub and reference heights while $z_{0}$ is the roughness length of the water surface which is generally very low. The turbine power curve follows the traditional shape with cut-in at $4 \mathrm{~m} / \mathrm{s}$, cutout at $25 \mathrm{~m} / \mathrm{s}$ and rated output at $15 \mathrm{~m} / \mathrm{s}$.

Given the cost of undersea cabling and the distance to shore, offshore wind farms, particularly those in deeper water will be more expensive than onshore, albeit that their energy capture is likely to be higher. For the purposes of illustration, assumed installed costs are $£ 1200 / \mathrm{kW}$ with operations and maintenance costs $(\mathrm{O} \& \mathrm{M})$ set higher than would be expected for onshore wind turbines. These and other economic data are given in Table 1.

Revenue is estimated at $£ 60 / \mathrm{MWh}$ which includes gains from wholesale energy sales, sales of Renewable Obligation Certificates (ROCs) (as set out in the UK Renewables Obligation [25]) and the net income from levies and market imbalance penalties.

\subsection{Wave Energy Converter}

In illustrating the wave energy appraisal, a WEC developed by Edinburgh-based Ocean Power Delivery Ltd [26] is used. The Pelamis is a $120 \mathrm{~m}$ long floating device that resembles a sea-snake with four articulated sections that flex (and produce up to $750 \mathrm{~kW}$ ) as waves run down the length of the device. A lack of directional information is not an issue with this device as it is self-referencing. It is designed to maximise production in normal sea conditions whilst surviving heavy seas $\left(H_{\mathrm{S}}>8 \mathrm{~m}\right)$ through power limitation. The power output matrix in Figure 5 gives the device output as a percentage of capacity for each sea state. The black line corresponds to the PM spectrum and the nearest grid value is assigned to the relevant sea state/wind speed increment. The cost of such a device is commercially sensitive, so representative capital 
and O\&M costs were estimated based on costs for other WECs [21]; again these are given in Table 1.

\subsection{Base Case Performance}

The base case represents the technical and economic performance of the wind turbine and WEC with the base wind speed of $10 \mathrm{~m} / \mathrm{s}$. Summaries are given in Tables 2 and 3, respectively.

\subsubsection{Wind}

With over a fifth of the year spent at rated output, wind turbine production is estimated at over $13 \mathrm{GWh}$. While the near $50 \%$ load factor is on the high side it is reflects the higher mean wind speeds available offshore as well as the use of the simpler Rayleigh, rather than the Weibull distribution. This is reflected in the economic performance of the turbine although the electricity cost of around $5 \mathrm{p} / \mathrm{kWh}$ is comparable with estimates from elsewhere (e.g. [27]).

\subsubsection{Wave}

The modelled weighted average significant wave height and period and the available wave power are in line with expected values for the North Atlantic albeit on the low side $(83 \mathrm{~kW} / \mathrm{m}$ compared with the $93 \mathrm{~kW} / \mathrm{m}$ suggested in [28]).

The resulting production and average power output are reasonable estimates although once again on the low side. This can be seen with the load factor being at the lower end of the range expected for such a device. It can be seen that the time during which the device is idle is around one third of the year, while peak output is achieved for only $5 \%$ of the year.

Given the assumptions made, the economic performance is in line with expectations for this non-mature technology (electricity cost in the region of 5 to $6 \mathrm{p} / \mathrm{kWh}$ ).

\subsection{Climate Sensitivity}

Changes in marine climate were simulated by altering the mean annual wind speed by up to $\pm 20 \%$ in $10 \%$ intervals. A summary of the changes to wind turbine performance are given in Table 2. A similar summary of wave climate estimates and device performance is shown in Table 3.

\subsubsection{Wind turbine performance}

As would be expected the cubic law means that the effect on production is marked; a 10\% decrease in wind speed lowers production by $12 \%$ (Figure 6). The change is comparable to the lower end of the range suggested elsewhere [15] and it is apparent that reductions have a proportionately greater impact, due mainly to the cubic law and that the rated capacity of the turbine precludes significant gains from higher 
wind speeds. Economically, the changes are significant with a $20 \%$ fall in wind speed raising unit electricity costs by $35 \%$.

\subsubsection{Wave climate}

Figure 7 shows the variation in mean wave height period and wave power within the range of wind speed changes. Wave period varies in direct proportion with the wind speed while wave height is more sensitive to increases in speed as might be expected from the square-relationship. The $20 \%$ rise in wind speed raises mean wave heights by around $44 \%$ (over a metre on average). The combined effect of changes in wave characteristics on available wave power is significant with the power relationship evident. For example, a $20 \%$ decrease in mean wind speed lowers available power levels by $67 \%$ while the opposite change raises them by $133 \%$.

\subsubsection{WEC Production}

The consequences of this level of sensitivity are significant for WEC energy production (Figure 8), with production varying by up to $800 \mathrm{MWh} / \mathrm{yr}(42 \%)$ for a $20 \%$ wind change. The WEC is less sensitive to increases in wind speed as wave powers in excess of rating are shed. This is illustrated by the proportion of time at rated output: under the conditions suggested by a $20 \%$ increase in mean wind, this duration increases to $12 \%$; it drops to less than $1 \%$ under the opposite scenario.

\subsubsection{WEC Economics}

The large changes in production, and in consequence, revenue have a significant impact on the economics of the WEC (Figure 9). Over the range of wind speeds examined, the Internal Rate of Return (IRR) varies by 12 percentage points and, following the production pattern, shows greater sensitivity to falling mean wind speed. Unit electricity costs show a variation of over three times over the range of winds with a $75 \%$ increase with the $-20 \%$ scenario.

\subsubsection{Relative Climate Sensitivity}

While the sensitivity of production and economics of the wind and wave projects to changes in mean wind speed appear to be significant, it is useful to compare this with other major project risk factors. Capital costs, O\&M costs and revenue were, in turn, altered by $\pm 10 \%$ of their original value and the IRR noted under base case wind conditions.

The results for both technologies are shown in Figure 10 alongside the comparable change in wind speed. For the wind turbine (right) the magnitude of change due to wind changes is slightly greater than that for capital cost and revenue with O\&M a good way behind. The sign of the changes reflects whether a reduction in that parameter is beneficial or adverse, economically. Overall, the WEC (left) appears to be more sensitive 
than the wind turbine although this is to some extent a feature of the different cost structure and the WEC's lower load factor (in this case at least). The relative sensitivity to non-wind parameters is similar to the wind turbine, but it clear that the WEC is significantly more sensitive to wind changes than any other which is clearly a result of the power law. Discount rate is another key project parameter and although IRR is not influenced by changes in discount rate (as it is the discount rate at which project value is zero) calculations with electricity costs suggests that the sensitivity lies between revenue and O\&M.

Overall, this comparison adds credibility to the view that changes in wind climate should be of concern for those developing, deploying and relying on future offshore wind and in particular WECs.

\section{Discussion}

While the impact of global warming-induced changes in wind climate has also been highlighted by other work, it is believed that this study is the first to address the consequent influence on the wave resource, its capture and the economics of devices. In both cases, a deliberately simple approach has been taken in order to get a quantitative appreciation of the potential changes. As a result, there are several limitations.

The Pierson-Moskowitz spectrum accounts only for wind-generated waves while swell, which can be significant in the North Atlantic, is not represented. This results in wave height, length and correspondingly, energy being under-predicted which explains the lower than expected wave heights and the poorer device performance. For example, a vertical shift in the PM spectrum in Figure 5 would allow the WEC to operate at rated for greater durations. Strictly speaking, the PM spectrum is only validated for wind speeds of up to $20 \mathrm{~m} / \mathrm{s}$ as few higher speed spectra were available in original study [22]. The issue is that it is assumed that the wave spectra are fully developed at higher wind speeds although this requires increases in storm duration and fetch. The authors believe that the use of wind speeds of up to $30 \mathrm{~m} / \mathrm{s}$ is reasonably reliable given the large fetch of the Atlantic, the low probabilities assigned by the Rayleigh distribution to higher wind speeds and the power limits enforced by the wave device in larger seas.

Monthly variations in both wind and wave climate are significant, particularly in the North Atlantic. Accordingly, this study cannot capture the subtleties of historic and potential wave climates. The development of a monthly model would be a useful extension.

Sea depth has a major bearing on the wave energy available at a given location (with shallower waters experiencing reduced energies) as well as on the costs of installation and maintenance of both wind turbines and WECs. Future studies that incorporate more sophisticated approaches will need to account for bathymetry.

While the operational differences between wind turbines models are relatively minor the same cannot be said 
of WECs. Their different developmental stages and operational and control strategies suggests that the response to wave climate changes will vary and further work needs to identify the relative vulnerability of a range of device types.

While the issue of device survivability is beyond the scope of this study, well-documented approaches could be applied to ascertain extreme wave heights and examine the impact on wind and wave installations.

Although this study has been a useful start in quantifying the extent to which marine energy may be vulnerable to changing climate, more sophisticated approaches will be necessary for detailed examination. The use of the proxy regressions to relate climate to wind and wave conditions appears to be a promising step, prior to the use of up-to-date wave models driven by current and GCM-derived future climate. With either approach there is potential to apply more sophisticated appraisal techniques (e.g. scenario and risk analyses) to the issue.

\section{Conclusions}

In common with other renewables, marine energy may be sensitive to changes in climate resulting from rising carbon emissions. Despite a lack of a proven link to global warming, evidence indicates that wind and wave climates have altered over recent decades. Future changes will affect energy capture and ultimately plant economics. Here, a relatively simple sensitivity study is used to quantify how changes in mean wind speed - as a proxy for wider climate change - influence wind and wave energy production and economics.

\section{Acknowledgements}

The authors are grateful for early discussions with Professor Stephen Salter and others in the Institute for Energy Systems at the University of Edinburgh; also to Matthew Bates and Lekha Yadav for their efforts in advancing areas of this work during their respective project work. 


\section{References}

[1] Garrad Hassan and Partners. Scotland's Renewable Resource. Edinburgh: Scottish Executive; 2001.

[2] Harrison GP, Whittington HW. Vulnerability of hydropower projects to climate change. IEE Proc. Gen. Transm. Dist. 2002;149(4):249-55.

[3] Breslow PB, Sailor DJ. Vulnerability of wind power resources to climate change in the continental United States. Renewable Energy 2002;27:585-98.

[4] Grevemeyer I, Herber R, Essen H-H. Microseismological evidence for a changing wave climate in the northeast Atlantic Ocean. Nature 2000;408:349-52.

[5] Carter DJT, Draper L. Has the north-east Atlantic become rougher? Nature 1988;332:494.

[6] Carter DJT, Bacon S. Wave climate changes in the North Atlantic and North Sea. Intl J Climatology 1991;11:545-58.

[7] Bacon S, Carter DJT. A connection between mean wave height and atmospheric pressure gradient in the North Atlantic. Intl J Climatology 1993;13:423-6.

[8] Watson GM, Halliday JA, Palutikof JP, Holt T, Barthelmie RJ, Coelingh JP, van Zuylen EJ, Cleijne JW. Predicting Offshore Wind Energy Resources (POWER), Final Report, 2001.

[9] Woolf DK, Challenor PG, Cotton PD. Variability and predictability of the North Atlantic wave climate. J Geophysical Research 2002;109(C10):3145-58.

[10] Günther H, Rosenthal W, Stawarz M, Carretero JC, Gomez M, Lozano I, Serrano O, Reistad M. The wave climate of the North-East Atlantic over the period 1955-1994: the WASA Wave Hindcast. The Global Atmosphere and Ocean System 1998;6:121-63.

[11] Swail VR, Ceccacci EA, Cox AT. The AES40 North Atlantic Wave Reanalysis: Validation and Climate Assessment. 6th International Workshop on Wave Hindcasting and Forecasting November 6-10, 2000, Monterey, California.

[12] Wang XL, Zwiers FW, Swail VR. North Atlantic Ocean wave climate change scenarios for the TwentyFirst Century, J Climate 2004;17:2368-83.

[13]Hulme M, Jenkins GJ, Lu X, Turnpenny JR, Mitchell TD, Jones RG, Lowe J, Murphy JM, Hassell D, Boorman P, McDonald R, Hill S. Climate change scenarios for the United Kingdom: the UKCIP02 Scientific report, Department for Environment, Food \& Rural Affairs; 2002.

[14] Segal M, Pan Z, Arritt RW, Takle ES. On the potential change in wind power over the US due to increases of atmospheric greenhouse gases. Renewable Energy. 2001;24:235-43.

[15] Baker RW, Walker SN, Wade JE. Annual and seasonal variations in mean wind speed and wind turbine energy production. Solar Energy 1990;45(5):285-9.

[16]Jeffrey DC, Keller GJ, Mollison D, Richmond DJE, Salter SH, Taylor JRM, Young IA. 4th Year Report on Edinburgh Wave Power Project. Edinburgh: University of Edinburgh; 1978.

[17] Salter SH. Private Communication; 2003.

[18] Manwell JF, McGowan JG, Rogers AL. Wind Energy Explained: Theory, Design and Application. Chichester: J. Wiley \& Sons; 2002.

[19] Mollison D. Wave Climate and the Wave Power Resource. In: Evans DV, Falcão AF de O, editors. Hydrodynamics of Ocean Wave-Energy Utilization, Berlin: Springer-Verlag; 1986:133-56.

[20] Health and Safety Executive. Wind and wave frequency distributions for sites around the British Isles, Offshore Technology Report 2001/030, London: Stationary Office; 2001.

[21] Thorpe TW. A Brief Review of Wave Energy (ETSU-R120), London: Department of Trade and Industry; 1999.

[22] Pierson WJ, Moskowitz L. A proposed spectral form for fully developed wind seas based on the similarity theory of A. A. Kitaigorodskii. J Geophysical Research 1964;69:5181-90.

[23] Young IR, Holland GJ. Atlas of the Oceans: Wind and Wave Climate. Oxford: Pergamon; 1996.

[24] Vestas Wind Systems A/S. V90-3.0 MW Product Brochure. Rinkøbing: Vestas; March 2004.

[25] Department of Trade and Industry. The Renewables Obligation Order 2002. London: Stationary Office; 2002.

[26] Ocean Power Delivery. Website at http://www.oceanpd.com.

[27]PB Power. The Cost of Generating Electricity, report to the Royal Academy of Engineering; 2004.

[28] Mollison D, Buneman OP, Salter SH. Wave power availability in the NE Atlantic. Nature 1976;263:223-36. 


\section{Tables}

Table 1: Assumed marine device cost and revenue data

\begin{tabular}{lcc}
\hline Item & Wind Turbine & Wave Device \\
Capital cost (£/kW installed) & 1200 & 1300 \\
Annual O\&M (\% of capital cost) & 3 & 3 \\
Economic Lifetime (years) & 20 & 30 \\
Revenue (£/MWh) & 60 & 60 \\
Discount rates applied $(\%)$ & $8 \& 15$ & $8 \& 15$ \\
\hline
\end{tabular}

Table 2: Wind turbine performance with Base Case and uniformly altered wind speed

\begin{tabular}{|c|c|c|c|c|c|}
\hline \multirow[t]{2}{*}{ Measure } & \multirow[t]{2}{*}{ Base Case } & \multicolumn{4}{|c|}{ Annual mean wind speed change } \\
\hline & & $-20 \%$ & $-10 \%$ & $+10 \%$ & $+20 \%$ \\
\hline Mean turbine output $(\mathrm{kW})$ & 1493 & 1104 & 1321 & 1618 & 1697 \\
\hline Production (GWh/yr) & 13.08 & 9.67 & 11.57 & 14.17 & 14.85 \\
\hline Load factor $(\%)$ & 49.8 & 36.8 & 44.0 & 53.9 & 56.5 \\
\hline Time at zero output $(\%)$ & 9.2 & 14.1 & 11.3 & 7.7 & 6.5 \\
\hline Time at rated output $(\%)$ & 22.1 & 10.4 & 16.3 & 27.1 & 31.1 \\
\hline Internal Rate of Return, IRR (\%) & 18.13 & 11.68 & 15.34 & 20.09 & 21.3 \\
\hline Unit cost $(\mathrm{p} / \mathrm{kWh}), 8 \%$ discount rate & 4.49 & 6.06 & 5.07 & 4.14 & 3.95 \\
\hline Unit cost $(\mathrm{p} / \mathrm{kWh}), 15 \%$ discount rate & 5.52 & 7.06 & 5.91 & 4.82 & 4.60 \\
\hline
\end{tabular}

Table 3: Wave energy and device performance with Base Case and uniformly altered wind speed

\begin{tabular}{lrrrrr}
\hline Measure & Base Case & \multicolumn{3}{c}{ Annual mean wind speed change } \\
& & $-20 \%$ & $-10 \%$ & $+10 \%$ & $+20 \%$ \\
Mean wave height, $H_{S}(\mathrm{~m})$ & & & & & \\
Mean wave period, $T_{\mathrm{e}}(\mathrm{s})$ & 2.70 & 1.73 & 2.19 & 3.27 & 3.88 \\
Mean available wave power $(\mathrm{kW} / \mathrm{m})$ & 6.25 & 5.00 & 5.63 & 6.88 & 7.50 \\
Mean device power output $(\mathrm{kW})$ & 83.7 & 27.5 & 49.5 & 134.4 & 205.6 \\
Production $(\mathrm{GWh} / \mathrm{yr})$ & 232.8 & 134.4 & 183.8 & 279.4 & 322.5 \\
Load factor $(\%)$ & 2.04 & 1.18 & 1.61 & 2.45 & 2.83 \\
Time at idle $(\%)$ & 31.0 & 17.9 & 24.5 & 37.3 & 43.0 \\
Time at capacity $(\%)$ & 34.80 & 48.7 & 41 & 29.7 & 25.7 \\
IRR $(\%)$ & 4.90 & 0.9 & 2.4 & 8.2 & 12.2 \\
Unit cost $(\mathrm{p} / \mathrm{kWh}), 8 \%$ & 9.36 & 2.45 & 6.18 & 12.16 & 14.63 \\
Unit cost $(\mathrm{p} / \mathrm{kWh}), 15 \%$ & 5.44 & 9.43 & 6.89 & 4.54 & 3.93 \\
& 8.48 & 14.68 & 10.74 & 7.06 & 6.12 \\
\hline
\end{tabular}




\section{Figure Captions}

Figure 1. Linking climate change and marine energy

Figure 2. PM Spectrum superimposed on Scatter Diagram.

Figure 3. Methodology for appraising WECs (after [21])

Figure 4. Climate-dependent WEC appraisal methodology

Figure 5. Pelamis output (\% of capacity) with $H_{\mathrm{S}}$ and $T_{\mathrm{e}}$ (and PM spectrum)

Figure 6. Wind turbine performance with mean wind speed changes

Figure 7. Mean wave height, period and power with mean wind speed change

Figure 8 . WEC mean power output, time at idle/capacity with mean wind speed change

Figure 9. WEC economic indicators with mean wind speed change

Figure 10. Change in IRR with project variables for both technologies 


\section{Figures}

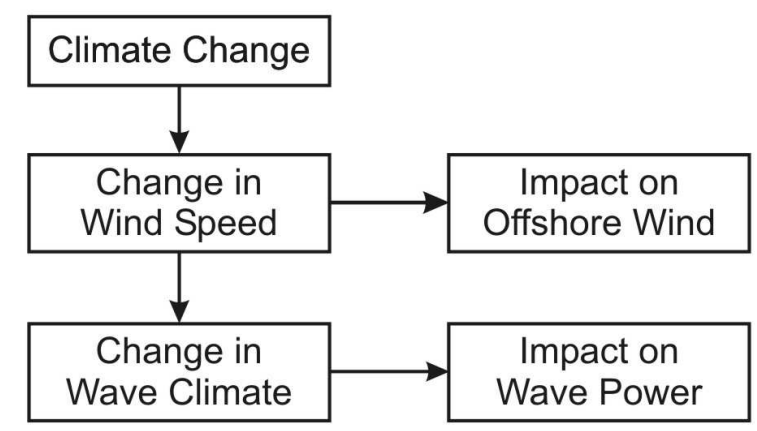

Figure 1. Linking climate change and marine energy

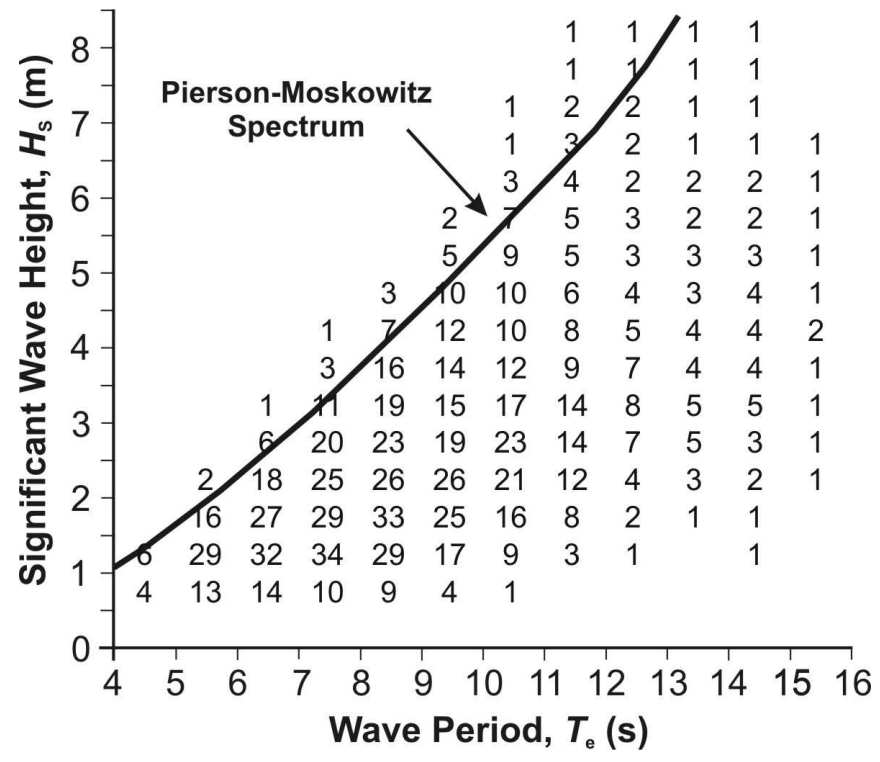

Figure 2. PM Spectrum superimposed on Scatter Diagram. 


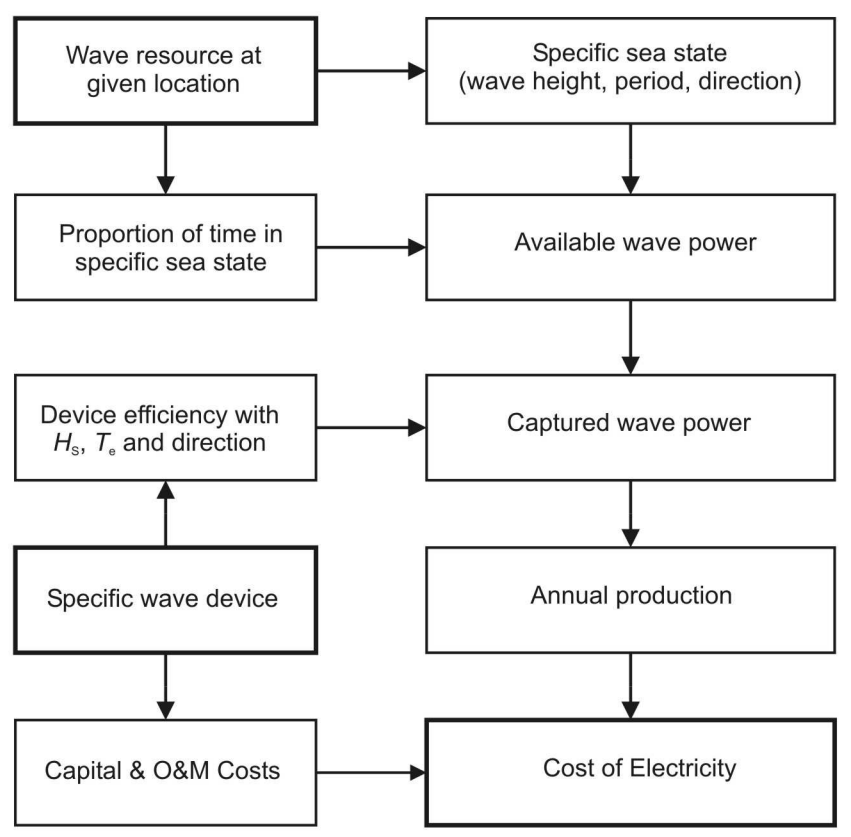

Figure 3. Methodology for appraising WECs (after [21])

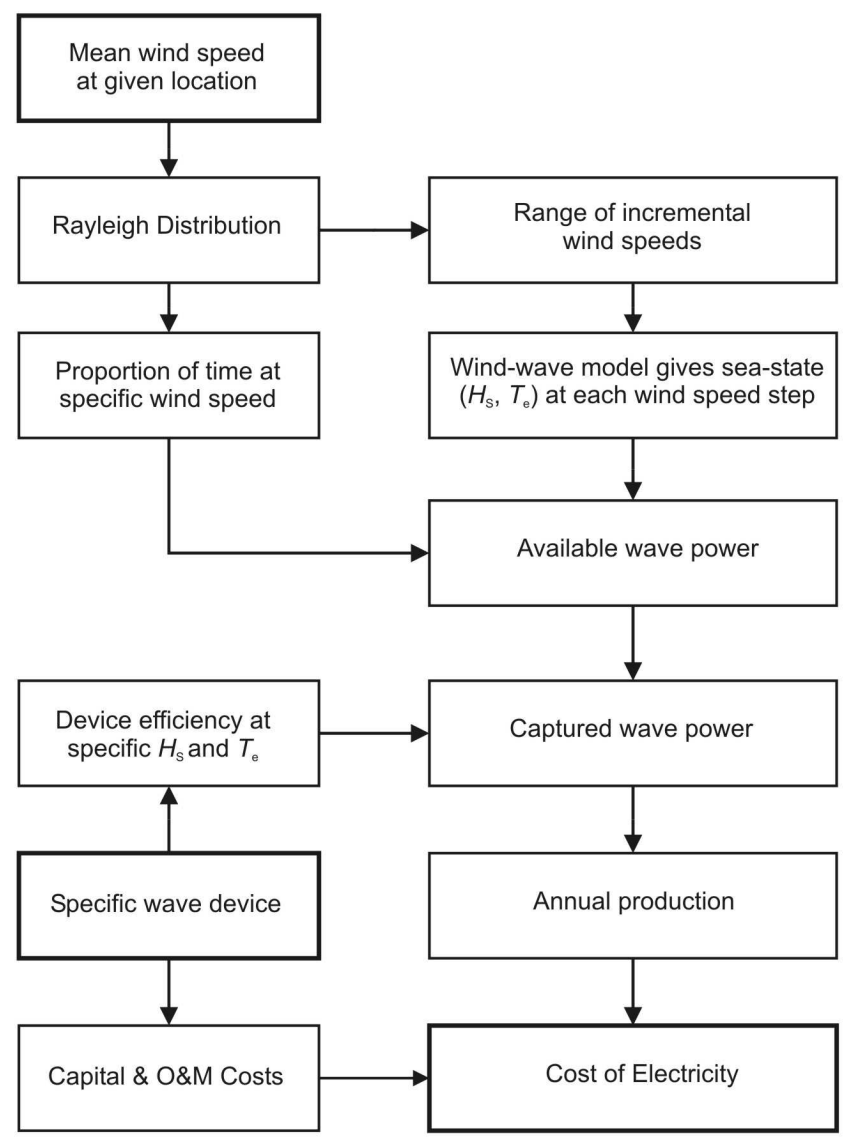

Figure 4. Climate-dependent WEC appraisal methodology 


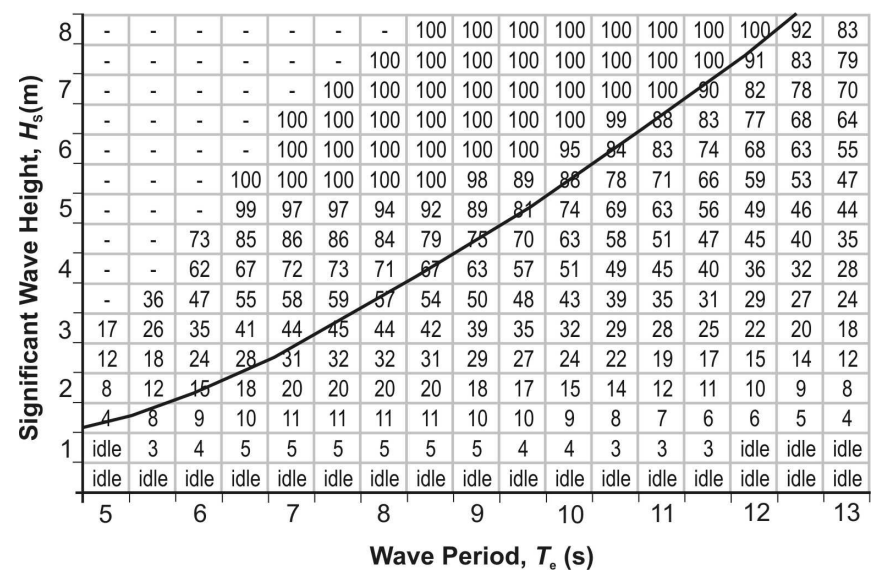

Figure 5. Pelamis output (\% of capacity) with $H_{\mathrm{S}}$ and $T_{\mathrm{e}}$ (and PM spectrum)

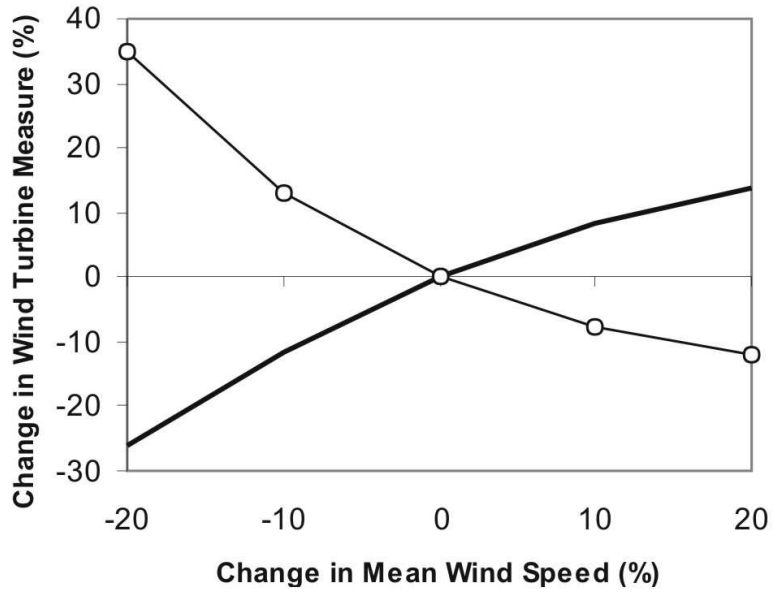

- Mean kW output $\quad-0-$ Unit cost, $8 \%$ discount rate

Figure 6. Wind turbine performance with mean wind speed changes 


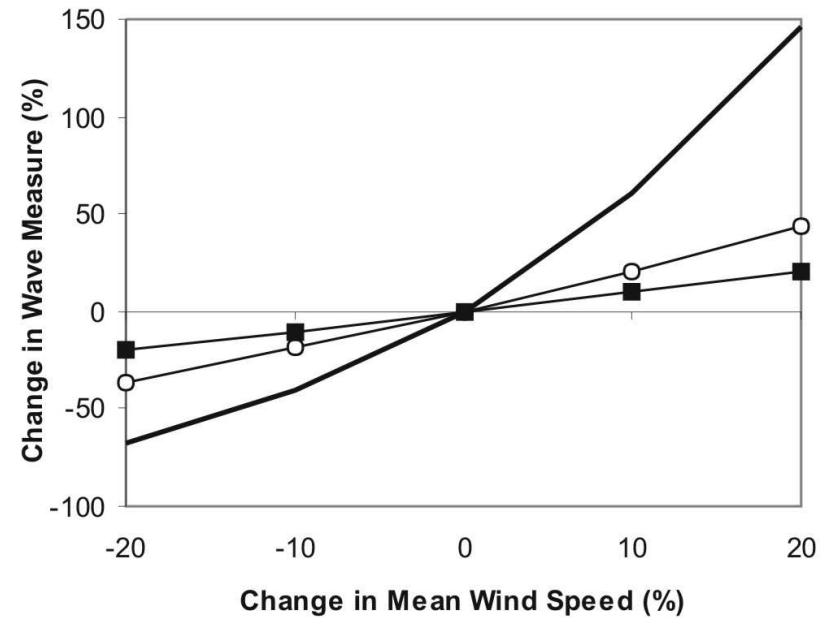

$\longrightarrow$ - Mean HS $\rightarrow$ Mean Te Mean wave pow er

Figure 7. Mean wave height, period and power with mean wind speed change

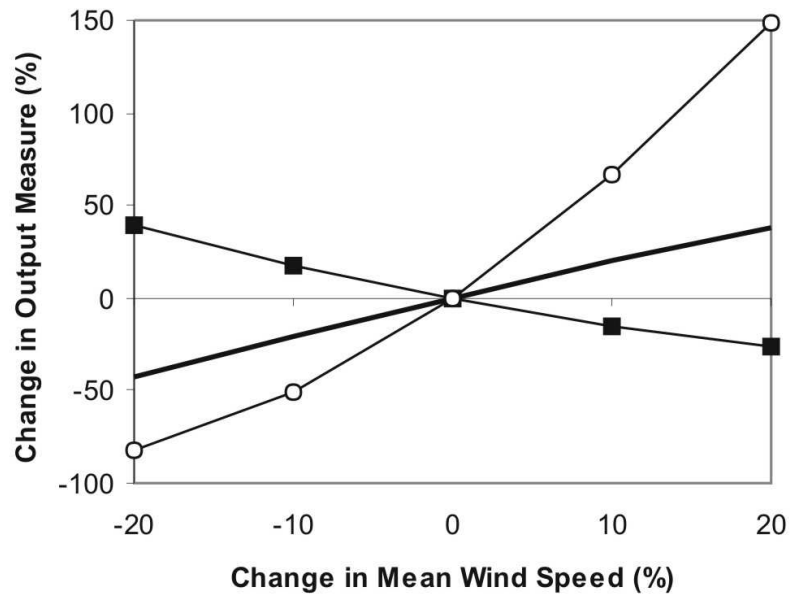

$\longrightarrow$ Mean kW output $\rightarrow$ - Idle $\quad \longrightarrow$ - At capacity

Figure 8 . WEC mean power output, time at idle/capacity with mean wind speed change 


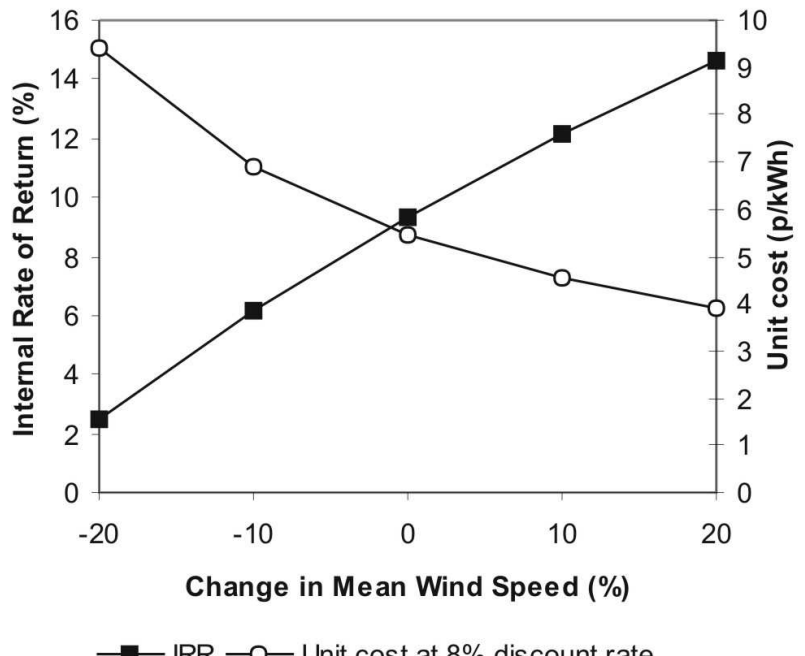

Figure 9. WEC economic indicators with mean wind speed change

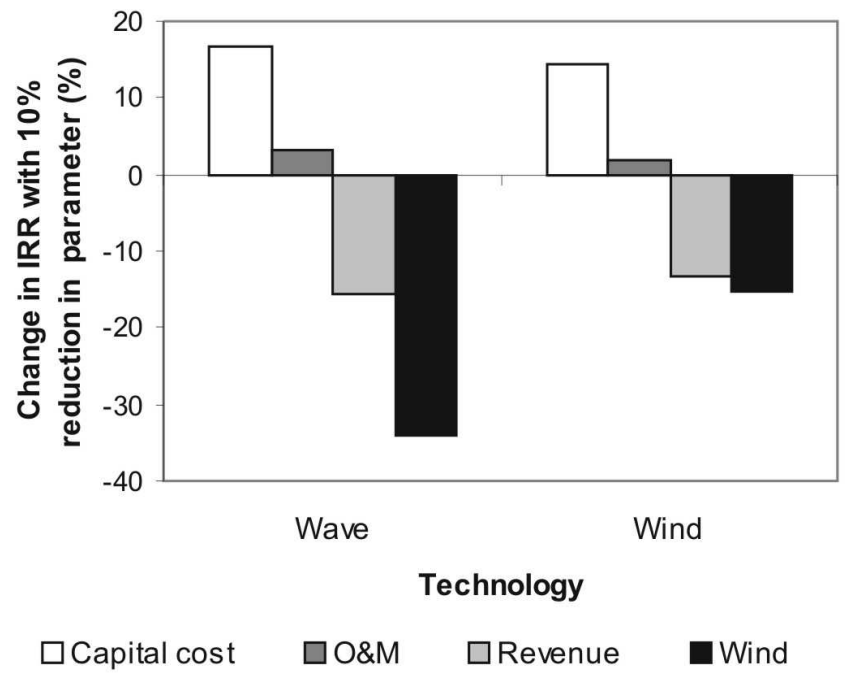

Figure 10. Change in IRR with project variables for both technologies 